\title{
Homicide-suicide and the role of mental disorder: a national consecutive case series
}

\author{
Sandra Flynn ${ }^{1} \cdot$ Linda Gask $^{2} \cdot$ Louis Appleby ${ }^{1} \cdot$ Jenny Shaw $^{1}$
}

Received: 16 September 2015/ Accepted: 16 March 2016/Published online: 16 April 2016

(c) The Author(s) 2016. This article is published with open access at Springerlink.com

\begin{abstract}
Purpose There is a lack of robust empirical research examining mental disorder and homicide-suicide. Primary care medical records are seldom used in homicide-suicide research. The aims of this study were to describe the characteristics of offenders and victims; determine the prevalence of mental disorder and contact with mental health services and examine adverse events prior to the offence.

Methods This was a mixed-methods study based on a consecutive case series of offences in England and Wales occurring between 2006 and 2008. 60 homicide-suicides were recorded. Data sources included coroner's records, police files, General Practice (GP) and specialist mental health records, and newspaper articles.

Results The results show that most victims were spouse/partners and/or children. Most perpetrators were male $(88 \%)$ and most victims were female $(77 \%)$. The incidents were commonly preceded by relationship breakdown and separation. $62 \%$ had mental health problems. A quarter visited a GP for emotional distress within a month of the incident. Few had been in recent contact with mental health services before the incident $(12 \%)$. Self-harm $(26 \%)$ and domestic violence (39\%) were common.
\end{abstract}

Sandra Flynn

sandra.m.flynn@manchester.ac.uk

1 The National Confidential Inquiry into Suicide and Homicide by People with Mental Illness, Centre for Mental Health and Safety, Institute of Brain Behaviour and Mental Health, University of Manchester, Jean McFarlane Building, Oxford Road, Manchester M13 9PL, UK

2 Institute of Population Health, University of Manchester, Williamson Building, Oxford Road, Manchester M13 9PL, UK
Conclusion In conclusion, GPs cannot be expected to prevent homicide-suicide directly, but they can reduce risk generally, via the treatment of depression and recognising the risks associated with domestic violence.

Keywords Homicide Suicide $\cdot$ Homicide-suicide Family violence $\cdot$ Mental illness $\cdot$ Depression

\section{Introduction}

Homicide-suicide is where an individual kills another person and then takes their own life. In the majority of cases the suicide occurs immediately. In our definition we have also included those who died within 3 days of the homicide, and cases where the offender was fatally injured at the time of the homicide, but died more than 3 days later. This is consistent with previous studies [1-3]. Over recent years, homicide-suicide has received increased academic attention, both empirically and theoretically, which has advanced our understanding of the phenomena. These acts are mostly carried out by men, the victims are most often female intimate partners or close family members, multiple victims are also common.

Explanations why people commit these acts have been proposed and classified in numerous typologies. Motivations include jealousy and revenge following real or perceived infidelity and relationship breakdown, altruism or mercy killing, financial problems and mental disorder [1, 4, 5]. However, these typologies have their limitations and do not comprehensively capture the complexities of homicide-suicide. Reliable information on the role of mental disorder in these cases is lacking. In a review of the literature spanning 60 years, Roma et al. (2012) found 30 studies presenting clinical findings, 20 reporting depression 
and 11 reporting psychosis [6]. Of these studies, the definition of mental disorder used have resulted in a wide variation in the prevalence rates reported $(18-75 \%)$ [7, 8]. Definitions of mental illness have included serious mental illness that required hospitalisation [7]; any treatment received from specialist mental health care services [2]; recorded history of mental illness documented by the police and/or medical examiners (National Violent Death Reporting System US) [9]; or having a post mortem diagnoses derived from medical records and/or informant descriptions of the deceased's mental state (psychological autopsy) [8]. Whilst these studies have provided valuable clinical insight, they are often based on subgroups such as filicide-suicide [10]; older couples [11]; or intimate-partner homicide-suicide [12-15]. Furthermore, the findings are commonly based on small regional samples [16-18]. Therefore due to the difficulties with data collection, national clinical studies of homicide-suicide are rare. Furthermore, mental disorder diagnosed by primary care and recorded in general practice medical records are seldom accessed.

In this study, we aimed to further our understanding of homicide-suicide by firstly describing the characteristics of offenders and victims. Secondly, we aimed to examine the clinical antecedents of these incidents (i.e. history of mental disorder, contact with mental health services, diagnosis, medication prescribed). Thirdly we aimed to examine adverse events prior to the offence (i.e. relationship breakdown and child custody disputes).

The low incident rate of homicide-suicide in England and Wales of 0.05 per 100,000 population (approximately 23 incidents per year) enabled a detailed exploration of the complex aetiology of these cases. Therefore, this is the first study to complete an in-depth examination using multiple data sources on a national consecutive case series of homicide-suicide.

\section{Materials and methods}

\section{Research design}

A mixed-method design was used to examine data from a national consecutive case series of homicide-suicides in England and Wales between 1st January 2006 and 31st December 2008. The case series was accessed via the National Confidential Inquiry into Suicide and Homicide by People with Mental Illness (NCISH) [3]. NCISH collate and maintain clinical data on homicide and suicide not replicated by any other national or international research group or organisation. Access to this data makes these finding unique. Additional information for both the qualitative and quantitative phases of the study were collected and analysed concurrently (i.e. both methods were used to explore the same research questions at the same time) [19].

\section{Sample: selection of participants}

A total of 83 people were initially suspected of carrying out a homicide-suicide over the study period. Twenty-three were excluded for reasons including; the perpetrator took their own life more than 3 days after the homicide (18 offenders); in 4 cases the coroner did not return an unlawful killing or suicide verdict; and in 1 case the inquest had not taken place at the time of analysis, and therefore a verdict had not been determined. The final sample consisted of 60 cases.

\section{Data collection}

Cases were identified using the existing NCISH homicidesuicide database. A detailed description of methodology for recording homicide-suicide incidents has been described previously [2]. To briefly summarise, notification of homicide-suicide incidents was received from the Home Office Statistics Unit of Home Office Science in most cases (92\%). The remaining cases not recorded on the homicide index were notified to NCISH via individual police forces. Data held on the NCISH database included demographic characteristics of the offender and victim, offence details and information regarding diagnosis and contact with mental health services. Once the offender had been identified, additional information was requested and obtained from coroners' files and police records ( $82 \%$ of cases), General Practice (GP) medical records (88\% of cases) and newspaper articles ( $90 \%$ of cases). The files contained antecedent information describing the events, circumstances and mental state of the offender leading up to the incidents which were specified in witness statements by friends and family members. GP medical records were examined to determine recent attendance, history of mental disorder, recent symptoms and medication prescribed. Triangulation of these data sources was undertaken to ensure the validity of responses. In instances of non-convergence between data sources, inconsistencies were reconciled by reviewing the evidence from all sources, discussing this amongst the authors and determining the most reasonable finding.

\section{Quantitative data analysis}

Data analysis was conducted using Stata version 11. Rates were calculated using ONS mid-year population estimates. Results were reported using $95 \%$ confidence intervals. If an item of information was not known for a case, the case 
was removed from the analysis of that item; the denominator in all estimates was the number of valid cases for each item and indicates the number of missing cases per item.

\section{Qualitative data analysis}

Documentary analysis was undertaken in accordance with Hodder [20]. The content of the documents such as the coroner's report, police investigation reports and witness statements were explored using framework analysis [21]. This systematic and comprehensive approach was undertaken in 5 key stages; familiarisation with the content of the documents; identifying an initial thematic framework; indexing or coding the data; charting the salient text to the framework; mapping themes and interpreting the meaning of these themes. An iterative approach was applied whereby the themes were repeatedly refined until saturation point was reached and no new themes emerged.

This method was preferred to the alternative of mapping to existing typologies $[1,5]$ as it enabled the generation of themes from our unique national consecutive case-series. Coding was undertaken by SF and the thematic framework was refined by SF, LG and JS during the iterative process.

\section{Results}

\section{The characteristics of perpetrators and victims}

During the 3 year study period 60 people, $4 \%$ of offenders took their own life after committing homicide, a rate of 0.04 per 100,000 population. The characteristics of offenders and victims are presented in Table 1. Most of the offenders were male. The median age was 44 . Half were married or cohabiting. The majority were white. Almost a third had a conviction for violence, including 3 offenders who had previously been convicted of homicide. The victims of the previous homicides were a former partner in 2 cases and an acquaintance in the remaining case. Over a third of offenders were found to have previously committed domestic violence. There were 70 victims in total, the majority of whom were female. The median age of the victims was 38. Nearly two-thirds of victims were the offender's spouse/partner (current or ex), of these 19 $(45 \%)$ had been in an intimate relationship for over 20 years. Twenty $(29 \%)$ children were killed by a parent (filicide) and 2 perpetrators killed a spouse/partner (current or ex) and children (familicide). In total, 6 offenders killed more than 1 victim. The highest number of victims killed in single incident was 5 .

\section{Method of homicide and suicide}

In the majority of incidents the offender took his or her own life within $24 \mathrm{~h}$ of committing homicide and this occurred most often in home shared by the offender and victim. The most common method of homicide was by sharp instrument, and hanging was the most frequently used method of suicide. The same method was used in both homicide and suicide in $24(40 \%)$ cases (Table 1).

\section{Adverse events prior to the homicide-suicide}

The most common circumstances leading to the individual's emotional distress was the loss of a close personal relationship either through imminent separation or divorce; or a significant change in the relationship due to the victim's ill health (e.g. dementia). Other adverse events included problems with children (child custody/access problems or the perpetrator's belief that they were failing as a parent); financial problems; and adjusting to a new social situation (either because they were a recent immigrant or a recently released prisoner). Most offenders had previously exhibited difficulty coping with emotional distress, resulted in violence and aggression or self-harm. Five ( $9 \%$ ) had previously been bereaved by the suicide of a family member or close friend. In 1 case the offender experienced the loss within 2 weeks of the homicide-suicide, in the remaining cases the deaths occurred more than 10 years before the homicide-suicide.

\section{History of mental disorder prior to the offence}

Fifty-six (93\%) offenders were registered with a GP practice. Data from GP medical records were obtained on $53(88 \%)$ offenders. The following analysis is based on those 53 cases on whom data were available (Table 2). Thirty-three $(62 \%)$ had previously been diagnosed with a mental disorder. The most common diagnosis was depression, psychosis was rare, and none of the offenders had been diagnosed with personality disorder. Nearly a third had been prescribed psychotropic medication at the time of the homicide-suicide, mostly antidepressants. A quarter had previously attempted suicide between 1 and 4 times. Overall, suicidal ideation was noted by a GP in 7 cases $(14 \%)$. Three quarters of the perpetrators had attended their GP within 12 months of the offence, $40 \%$ within a month. A third of offenders were recorded as having discussed psychological problems with their GP within a year of the offence, a quarter within a month.

A response to our inquiry regarding contact with specialist mental health services was received on all 60 offenders. The majority $(46,77 \%)$ had no previous contact with mental health services. Of the fourteen $(23 \%)$ who 
Table 1 Characteristics of homicide-suicide

\begin{tabular}{|c|c|c|c|}
\hline Offender characteristics & $N=60$ & Valid (\%) & $95 \% \mathrm{CI}$ \\
\hline \multicolumn{4}{|l|}{ Demographic characteristics } \\
\hline Age of offender: median (range) & 44 & $(18-85)$ & \\
\hline Male offender & 53 & $88 \%$ & $80-97$ \\
\hline Married/cohabiting & 32 & $53 \%$ & $40-66$ \\
\hline Married but separated & 7 & $12 \%$ & $3-20$ \\
\hline Unemployed & 16 & $28 \%$ & $16-40$ \\
\hline Living alone & 9 & $15 \%$ & $9-25$ \\
\hline Black or minority ethnic group & 17 & $29 \%$ & $17-41$ \\
\hline Born outside the UK & 14 & $24 \%$ & $13-35$ \\
\hline \multicolumn{4}{|l|}{ Behavioural features } \\
\hline History of alcohol misuse & 15 & $28 \%$ & $16-41$ \\
\hline History of drug misuse & 13 & $23 \%$ & $12-35$ \\
\hline Any previous conviction & 27 & $45 \%$ & $32-58$ \\
\hline Previous conviction for violence & 18 & $30 \%$ & $18-42$ \\
\hline Previously committed domestic violence & 22 & $39 \%$ & $26-52$ \\
\hline History of self-harm/attempted suicide & 14 & $26 \%$ & $14-38$ \\
\hline Previously bereaved by suicide & 5 & $9 \%$ & $2-17$ \\
\hline \multicolumn{4}{|l|}{ Offence characteristics } \\
\hline Suicide occurred $<24 \mathrm{~h}$ after homicide & 51 & $85 \%$ & $76-94$ \\
\hline Homicide occurred in shared home & 31 & $52 \%$ & $39-65$ \\
\hline Suicide occurred in shared home & 25 & $42 \%$ & $29-55$ \\
\hline \multicolumn{4}{|l|}{ Method of homicide } \\
\hline Sharp instrument & 22 & $37 \%$ & $24-49$ \\
\hline Asphyxia (strangulation/suffocation) & 18 & $30 \%$ & $18-42$ \\
\hline Firearms & 6 & $10 \%$ & $2-18$ \\
\hline \multicolumn{4}{|l|}{ Method of suicide } \\
\hline Hanging & 20 & $33 \%$ & $21-45$ \\
\hline Cutting/stabbing & 10 & $17 \%$ & $7-26$ \\
\hline Firearms & 5 & $8 \%$ & $1-15$ \\
\hline Self-poisoning & 5 & $8 \%$ & $1-15$ \\
\hline Drowning & 5 & $8 \%$ & $1-15$ \\
\hline Same method used in homicide and suicide & 24 & $40 \%$ & $28-52$ \\
\hline Victim characteristics & $N=70$ & Valid $(\%)$ & $95 \% \mathrm{CI}$ \\
\hline \multicolumn{4}{|l|}{ Demographic characteristics } \\
\hline Age of victim: median (range) & 38 & $(1-85)$ & \\
\hline Female victim & 54 & $77 \%$ & $67-87$ \\
\hline Unemployed & 11 & $16 \%$ & $7-26$ \\
\hline Ethnic minority & 15 & $21 \%$ & $10-30$ \\
\hline \multicolumn{4}{|l|}{ Relationship of victim to perpetrator } \\
\hline Spouse/partner (current or ex) & 45 & $64 \%$ & $53-76$ \\
\hline Child or stepchild & 20 & $29 \%$ & $18-39$ \\
\hline Multiple victims killed in an incident & 6 & $10 \%$ & $2-18$ \\
\hline Victims were spouse/partner and children (familicide) & 2 & $3 \%$ & $1-8$ \\
\hline
\end{tabular}

had a history of contact 7 were former patients and 7 had been under mental health care within 12 months of the offence, most commonly for depression. Ten (19\%) had previously been admitted as an in-patient (Table 2).

\section{Classifying homicide-suicide}

The homicide-suicide offenders diverge into two groups, firstly offenders with a history of depression and secondly 
Table 2 Mental disorder recorded in medical records

\begin{tabular}{|c|c|c|c|}
\hline Clinical characteristics & $N=53$ & Valid $(\%)$ & $95 \% \mathrm{CI}$ \\
\hline \multicolumn{4}{|l|}{ Evidence of mental illness } \\
\hline Diagnosis and prior treatment for mental illness (lifetime) & 33 & 62 & $49-76$ \\
\hline \multicolumn{4}{|l|}{ Primary diagnosis } \\
\hline Depressive disorder & 28 & 53 & $39-67$ \\
\hline (Situational depression) & $(6)$ & 12 & $4-23$ \\
\hline Other diagnosis (e.g. stress/anxiety) & 2 & 4 & $0-9$ \\
\hline Schizophrenia and other delusional disorders & 1 & 2 & $0-6$ \\
\hline Alcohol dependence & 1 & 2 & $0-6$ \\
\hline Drug dependence & 1 & 2 & $0-6$ \\
\hline No mental illness & 20 & 38 & $24-51$ \\
\hline \multicolumn{4}{|l|}{ Medication } \\
\hline Psychotropic medication prescribed at the time of the offence & 14 & 30 & $17-44$ \\
\hline \multicolumn{4}{|l|}{ Contact with GP services } \\
\hline \multicolumn{4}{|l|}{ Recent contact with GP } \\
\hline Contact within 12 months of the offence & 41 & 77 & $66-89$ \\
\hline Contact within 1 month of the offence & 21 & 40 & $26-53$ \\
\hline \multicolumn{4}{|l|}{ Contact with for psychological problems } \\
\hline Contact within 12 months of the offence & 22 & 42 & $28-55$ \\
\hline Contact $<1$ month prior & 15 & 28 & $16-41$ \\
\hline Contact with mental health services & \multicolumn{2}{|c|}{ Valid $(\%)$} & $95 \% \mathrm{CI}$ \\
\hline Any previous contact with MH services & \multicolumn{2}{|l|}{23} & $13-34$ \\
\hline Contact within 12 months of the offence & \multicolumn{2}{|l|}{12} & $4-20$ \\
\hline Contact $<1$ month prior & \multicolumn{2}{|l|}{7} & $0-13$ \\
\hline
\end{tabular}

offenders with a history of perpetrating domestic violence. Of the first group with depression $(n=28), 16(57 \%)$ had consulted a GP a month before the incident, mostly to discuss psychological problems. Eleven (41\%) had previously self-harmed/attempted suicide. Most depressed patients had been prescribed psychotropic medication at the time of the incident $(23,85 \%)$. The most common adverse incident reported by witnesses in this group (aside from mental illness) was separation from their partner (12, $46 \%)$. The second group identified were offenders with a history of committing domestic violence $(22,39 \%)$. Of these $22,14(64 \%)$ had previous convictions, this included violent offences in $11(50 \%)$. A history of substance misuse was common $(10 / 19,53 \%)$. Separation from a partner was the most common adverse event to occur prior to the homicide $(11 / 21,52 \%)$. There was an overlap of 7 offenders who had both a history of mental illness and of committing domestic violence.

\section{Discussion}

This is the only study to our knowledge to have undertaken an in-depth examination of homicide-suicide and mental disorder on a national case-series using data from primary care and specialist mental health services. The use of information from a variety of robust data sources and utilising a mixed method research design makes this study unique. We found that perpetrators of homicide-suicide in this study were commonly middle-aged white males, who recently experienced a relationship breakdown. Mental disorder, particularly depression was common. Almost two-thirds of those on whom medical records were obtained had previously been diagnosed with a mental disorder. Although the overall proportion with mental disorder was high, the majority did not have serious mental illness requiring care under specialist mental health services. This is consistent with NCISH data on convicted homicide offenders $(10 \%)$ but was lower than the proportion of people who died by suicide in recent contact with mental health services in England (28\%) [3]. It was more common for the offender to be seen by primary care services. Contact with GP services within a year of the incident $(77 \%)$ and within a month $(40 \%)$ was remarkably similar to the proportion of service contact in deaths by suicide in the general population, $77 \%$ and $45 \%$ respectively [22]. Almost a third had been prescribed antidepressants at the time of the offence but we were unable to confirm if medication was being taken as instructed. Non-adherence is estimated to occur in $50 \%$ of 
patients prescribed antidepressants, which can lead to an increased risk of adverse symptoms [23, 24].

Domestic violence was found to be an important feature of these cases, with over a third of offenders having previously assaulted a partner, similar to previous studies [25, 26]. However, few of these offenders had a history of mental disorder. This contrasts with findings from a US psychological autopsy study that found most offenders had a history of domestic violence as well as depression [27]. We recognise that personality disorder was likely to be under reported in this case series, as the diagnosis was not recorded in either the primary care or mental health service medical records. Knoll and Hatters-Friedman (2015) reported $17 \%$ of perpetrators had antisocial personality disorder, but their sample size was limited $(n=18)$ [27]. It is challenging to identify personality traits retrospectively in a deceased offender. A potential solution would be use document-derived assessments instruments such as the PAS-DOC [28] to examine the possible association between personality disorder and homicide-suicide.

\section{Recognising and treating patients at risk}

We found the proportion of people who committed homicide-suicide and had a history of mental illness was consistent with previous studies using a broadly similar methodological approach [29, 30]. However, the proportion was much higher than reported in US samples [9, 25]. The literature shows that these acts are commonly carried out by middle-age men, which supports the evidence that this is an emerging high risk group for suicide [31]. Personal loss through relationship breakdown at this stage in life has been shown to be an important trigger in these incidents [32], but the causes of homicide-suicide extend beyond emotional stress arising from relationship difficulties (which are not uncommon problems). The key factor associated with homicide-suicides is the individual's lack of resilience and inability to cope with stressful events, evidenced by their reaction to previous similar experiences, either responding violently towards themselves or other people. Despite this recorded history of high risk behaviour and emotional instability these factors were not commonly explored by GPs through routine enquiry. Previous research has highlighted a reluctance to discuss emotional problems with patients in fear of opening 'Pandora's box' [33]. However, such discussions are necessary to differentiate between emotional distress and a diagnosis of mental disorder requiring referral to specialist mental health services.

\section{Limitations}

There are inherent difficulties in using retrospective data and documents originally generated for non-research purposes that can introduce bias. However, given the low base rate of these events and the fact that both parties involved are deceased, data are often limited and difficult to obtain. We carried out a retrospective analysis of medical records to determine whether the offender had been diagnosed with any mental disorder. The shortcomings identified in using diagnoses recorded in official documents to measure mental illness were; (1) the true prevalence of mental illness may be underestimated as medical help is not always sought by people experiencing mental health problems; (2) the reliability of the recorded diagnoses has not been verified and there are likely to be inconsistencies between cases; (3) it is not known whether the diagnostic data in this study accurately reflects actual symptom-based diagnoses in a reliable and valid way.

There are also difficulties in determine a person's mental state at the time of offence based on descriptions provided in documents. This can only be achieved reliably through interviews and a psychiatric assessment of the individual following the offence, which is not possible with homicide-suicide offenders. In addition, due to the methodology used in this study we cannot state that there was a causal relationship between mental illness and the offence. We have therefore referred to the individual's history of mental illness or depression, and acknowledge that although a person may have a history of mental illness, they may not have had active symptoms at the time of offence, or impaired functioning. Despite the shortcomings, we consider this to be the most robust method available for defining mental illness in this population. Corroborating the findings from numerous sources of data through triangulation provided validity and rigour to the findings and helped to enhance our understanding of these events.

\section{Clinical implications}

It would be unrealistic to expect GPs or psychiatrists to prevent homicide-suicide directly, as these incidents are relatively rare and few clinicians will ever experience this phenomenon. There are however, improvements in service delivery that could help to reduce the number of incidents. For example the recognition and better treatment of mental disorder, particularly depression in primary care is achievable. Previous research has found that people with serious mental health problems, particularly major depression, are more likely to visit their GP, which demonstrates help seeking behaviour and a willingness to engage [34, 35]. It is of course more difficult to recommend preventative action for people not under the care of health services. Our findings suggest that only a quarter of the offenders who experienced emotional distress contacted their GP for psychological support in the weeks before the incident, the majority did not. Previous research has shown 
that people may be reluctant to engage with services due to self-stigma (personal views about mental illness) [36] and the public stigma (society's perception of mental illness) [37]. Therefore, it is important to promote campaigns to reduce stigma and to raise awareness of the wide range of support available and how this can be accessed. Initiatives in the voluntary sector such as State of Mind are a good example of how this can been achieved. The organisation raises awareness of mental health issues through sport, working to improve the mental health of professional and amateur rugby league players, the wider community and students at local colleges [38].

Secondly, our data has shown a small proportion of homicide-suicide offenders had mental illness and a history of committing intimate partner violence. A recent meta-analysis has shown an association between domestic violence perpetration and mental illness [39]. Men with depression were shown to have an almost 3-fold increase risk of committing intimate partner violence. However, the evidence base is currently insufficient, and more research is required to identify risk factors which will inform prevention strategies. Increasing our knowledge of risk factors in this population will help to reduce the risk of future incidents.

\section{Ethical considerations}

The study received MREC approval on 9th April 2008 and is registered under the Data Protection Act. Exemption under section 251 of the NHS Act 2006 (formerly section 60 of the Health and Social Care Act 2001) was obtained enabling access to confidential and identifiable information without informed consent in the interest of improving patient care (approved 23rd October 2008). Research governance approval was sought from 49 Primary Care Trusts in England and Wales. The study was registered under the Data Protection Act (1998). The authors assert that all procedures contributing to this work comply with the ethical standards of the relevant national and institutional committees on human experimentation and with the Helsinki Declaration of 1975, as revised in 2008.

Acknowledgments The study was carried out as part of the National Confidential Inquiry into Suicide and Homicide by People with Mental Illness. The authors acknowledge the help of coroners, police forces and primary care trusts for providing access to their data. The authors thank other members of the research team.

Funding NCISH is commissioned by the Healthcare Quality Improvement Partnership (HQIP) and funded by NHS England; the Scottish Government; Welsh Government; the Northern Ireland Department of Health, Social Services and Public Safety and the States of Jersey and Guernsey. This research received no specific grant from any funding agency, commercial or not-for-profit sectors.

\section{Compliance with ethical standards}

Conflict of interest LA is a non-executive board member of the Care Quality Commission (CQC).

Open Access This article is distributed under the terms of the Creative Commons Attribution 4.0 International License (http://crea tivecommons.org/licenses/by/4.0/), which permits unrestricted use, distribution, and reproduction in any medium, provided you give appropriate credit to the original author(s) and the source, provide a link to the Creative Commons license, and indicate if changes were made.

\section{References}

1. Marzuk PM, Tardiff K, Hirsch CS (1992) The Epidemiology of Murder-Suicide. JAMA 267:3179-3190

2. Flynn S, Swinson N, While D, Hunt IM, Roscoe A, Rodway C, Windfuhr K, Kapur N, Appleby L (2009) Homicide followed by suicide: a cross-sectional study. J Forens Psychiatry Psychol 20:306-321

3. National Confidential Inquiry into Suicide and Homicide by People with Mental Illness (NCISH) (2014a) Annual Report: England, Northern Ireland, Scotland and Wales July 2014. University of Manchester: Manchester.(http://www.bbmh.manchester.ac.uk/ $\mathrm{cmhs} /$ centreforsuicideprevention/nci/reports/Annualreport2014. pdf) Accessed 20 May 2015

4. Hannah SG, Turf EE, Fierro MF (1998) Murder-suicide in central Virginia: a descriptive epidemiologic study and empiric validation of Hanzlick-Koponen typology. Am J Forensic Med Pathol 19:275-283

5. Hanzlick R, Koponen M (1994) Murder-suicide in Fulton County, Georgia, 1988-1991. Comparison with a recent report and proposed typology. Am J Forensic Med Pathol 15:168-173

6. Roma P, Pazzelli F, Pompili M, Lester D, Girardi P, Ferracuti S (2012) Mental illness in homicide-suicide: a review. J Am Acad Psychiatry Law 40:462-468

7. Virkkunen M (1974) Suicide linked to homicide. Psychiatr Q 48:276-282

8. Rosenbaum M (1990) The role of depression in couples involved in murder-suicide and homicide. Am J Psychiat 147:1036-1039

9. Logan J, Hill HA, Black ML, Crosby AE, Karch DL, Barnes JD, Lubell KM (2008) Characteristics of perpetrators in homicidefollowed-by-suicide incidents: national violent death reporting system-17 US states, 2003-2005. Am J Epidemiol 168:1056-1064

10. Friedman SH, Hrouda DR, Holden CE, Noffsinger SG, Resnick PJ (2005) Filicide-suicide: common factors in parents who kill their children and themselves. J Am Acad Psychiatry Law 33:496-504

11. Cohen D, Llorente M, Eisdorfer C (1998) Homicide-suicide in older persons. Am J Psychiat 155:390-396

12. Easteal P (1994) Homicide-suicides between adult sexual intimates: an Australian Study. Suicide Life Threat Behav 24:140-151

13. Malphurs JE, Cohen D (2005) A statewide case-control study of spousal homicide-suicide in older persons. Am J Geriatri Psychiatry $13: 211-217$

14. Koziol-McLain J, Webster D, McFarlane J, Block CR, Ulrich Y, Glass N, Campbell JC (2006) Risk factors for femicide-suicide in abusive relationships: results from a multisite case control study. Violence Vict 21:3-21 
15. Krulewitch CJ (2009) Epidemiology of intimate partner homicide-suicide events among women of childbearing age in Maryland, 1994-2003. Am J Forensic Med 30:362-365

16. Milroy CM (1993) Homicide followed by suicide (dyadic death) in Yorkshire and Humberside. Med Sci Law 33:167-171

17. Bourget D, Gagne P, Moamai J (2000) Spousal homicide and suicide in Quebec. J Am Acad Psychiatry Law 28:179-182

18. Campanelli C, Gibson T (2002) Murder-suicide in new Hampshire. Am J Forensic Med Pathol 23:248-251

19. Creswell JW, Plano Clark VL (2007) Designing and conducting mixed methods research. Sage, Thousand Oaks

20. Hodder I (2003) The interpretation of document and material culture. In: Denzin NK, Lincoln YS (eds) Collecting and interpreting qualitative materials. Sage, London, pp 155-175

21. Ritchie J, Spencer L (1994) Qualitative data analysis for applied policy research. Analyzing qualitative data, Routledge

22. National Confidential Inquiry into Suicide and Homicide by People with Mental Illness (NCISH) (2014) Suicide in primary care in England: 2002-2011. University of Manchester, Manchester

23. World Health Organization (2003) Adherence to long-term therapies: evidence for action. World Health Organization, Geneva

24. Farinde A (2013) Adherence to antidepressants. Arch Phar Pract 4:44-46

25. Salari S, Sillito CL (2016) Intimate partner homicide-suicide: perpetrator primary intent across young, middle, and elder adult age categories. Aggress Violent Beh 26:26-34

26. Dogan KH, Demirci S, Gunaydin G, Buken B (2010) HomicideSuicide in Konya, Turkey Between 2000 and 2007. J Forensic Sci 55:110-115

27. Knoll JL, Hatters-Friedman S (2015) The homicide-suicide phenomenon: findings of psychological autopsies. J Forensic Sci 60:1253-1257

28. Tyrer P (2007) Critical developments in the assessment of personality disorder. B J Psych 190(Supplement 49):s51-s59
29. Lindqvist P, Gustafsson L (1995) Homicide followed by the offender's suicide in northern Sweden. Nord J Psych 49:17-24

30. Moskowitz A, Simpson AIF, McKenna B, Skipworth J, BarryWalsh J (2006) The role of mental illness in homicide-suicide in New Zealand, 1991-2000. J Forens Psychiatry Psychol $17: 417-430$

31. Department of Health (2012) Preventing suicide in England: a cross-government outcomes strategy to save lives. Department of Health, London

32. Liem M, Barber C, Markwalder N, Killias M, Nieuwbeerta P (2011) Homicide-suicide and other violent deaths: an international comparison. Forensic Sci Int 207:70-76

33. Mitchell AJ, Vaze A, Rao S (2009) Clinical diagnosis of depression in primary care: a meta-analysis. Lancet 374:609-619

34. King M, Nazareth I, Levy G, Walker C, Morris R, Weich S, Bellón-Saameño JA, Moreno B, Švab I, Rotar D, Rifel J, Maaroos HI, Aluoja A, Kalda R, Neeleman J, Geerlings MI, Xavier M, Caldas de Almeida M, Correa B, Torres-Gonzalez F (2008) Prevalence of common mental disorders in general practice attendees across Europe. B J Psych 192:362-367

35. Pearson A, Saini P, Da Cruz D, Miles C, While D, Swinson N, Williams A, Shaw J, Appleby L, Kapur N (2009) Primary care contact prior to suicide in individuals with mental illness. Br J Gen Pract 59:825

36. Link BG, Phelan JC (2001) Conceptualizing stigma. Ann Rev Soc 27:363-385

37. Corrigan PW (2000) Mental health stigma as social attribution: Implications for research methods and attitude change. Clin Psych Sci Prac 7:48-67

38. State of Mind (http://stateofmindrugby.com). Accessed 20 May 2015

39. Oram S, Trevillion K, Khalifeh H, Feder G, Howard LM (2014) Systematic review and meta-analysis of psychiatric disorder and perpetration of partner violence. Epidemiol Psychiatr Sci $23: 361-376$ 